\title{
Research of Achievement Motivation in Neurotic and Stress-related Disorders
}

\author{
N. B. Zhiyenbayeva, B. B. Beisekeyeva, A. E. Abdrakhmanov, O. B. Tapalova*
}

\author{
Kazakh Academy of Labor and Social Relations, Almaty, Kazakhstan \\ Abai Kazakh National Pedagogical University, Almaty, Kazakhstan. \\ *Corresponding author. E-mail: otapalova@gmail.com
}

Paper received 21.05.18; Accepted for publication 29.05.18.

\author{
https://doi.org/10.31174/SEND-HS2018-168VI27-10
}

\begin{abstract}
This paper highlights results of research and analysis of achievement motivation's patterns at neurotic and stress-related disorders. Interest to research of this medical-psychological problem is connected with goals of changing of motivation's pathological patterns among this group of individuals. The research sample included 65 respondents of psychotherapeutic department. The study was conducted using the following methods: test by Hekhauzen; test "Diagnostics of motivational structure of personality" by Milman, questionnaires "Big Five" Obtained results of research show that neuroses in people are the result of internal conflict and anxiety.
\end{abstract}

Keywords: achievement motivation, neurasthenia, hypochondriacal and obsessive-compulsive disorder, anxiety, depression.

1. Introduction. The problem of achievement motivation, related to actual problems of psychology, as it combines a set impelling factors that are necessary for understanding and explaining the reasons, focus and implementation mechanisms of human behaviour.

This problem gets special urgency in the case of failure of achievement motivation or incentive distortions of components because of psychological difficulties, mental pathology.

Today, there are a lot of experimental data covering the understanding of the phenomenon of achievement motivation. Each theory contributes to the development of ideas of this important construct, highlighting certain aspects and problems. The most productive for the development of further studies could be the following: motivation to achieve - is a construct that describes the range of factors that provide the direction of the subject for the best performance of activities aimed at achieving a certain result, which can be applied the criterion of success $[4,9]$.

Experience of prolonged failure is an external predictor of reduces expectations of subject regarding his future success and negative impact on the resulting achievement motivation [6]. Attractive results and belief in a positive outcome are not enough to update the achievement motivation. There should be a belief in your abilities - selfefficacy [1].

Internal sources, such as a sense of own choice, satisfaction from the process of activities implementation, interest clearly affect the motivation to achieve [1, 4]. Main disturbances in the formation and functioning of motives: the pathology of structural and content aspect of the motivational sphere, the violation of motivation, the oppression of motives, motives and inclinations strengthening, distortion of motives, impulses and instincts refer to the pathology of personality's motivational sphere [10].

In disorders that scholars and practitioners often call "boundary psychiatry" is characterized by specific disorders of motivational sphere. The main subject of studies is nosologic groups, which include such forms of neurosis as histrionic personality disorder and obsessivecompulsive disorder.

Neurasthenia occurs predominantly in the long-acting traumatic factors. For a person with neurasthenia easy excitability at fast exhaust, variability of emotions and unstable, often low mood, changes and vegetative sphere due to a variety of disorders of the nervous system are peculiar. In addition, there is a disturbed sleep, in some cases, anxiety or fear. Hysteria is diverse in its manifestations. There are numerous cases of movement disorders (disorders of coordination, paralysis), disorders of pain sensation, sensory (hysterical blindness, deafness).

Obsessive-compulsive personality disorder manifests itself in irritability, fatigue, sleep disorders, autonomic disorders but is the presence of human obsessions, often in the form of phobias, is the main characteristic.

All these forms of neurosis are the result of internal conflicts that arise in people on different occasions. Neurotic conflict is a contradiction between the desire of the individual, when inflated self-requirements and its capabilities. For neurasthenia predisposed people with strong drives, which are not able to satisfy them adequately are common. They differ a great responsibility, different rules are perceived dogmatically excluding situations are reviewed with great difficulty when faced with reality; painfully tolerate ambiguity when the situation is unknown. Hysterical conflict arises because of the excessively exaggerated claims individual requirements while others exceed the demands on themselves. The desire to stand out, to satisfy his whim combined with complete disregard or underestimation of the actual conditions and requirements of others. Psychasthenic conflict arises due to conflicting needs, the struggle between desire and duty, between moral principles and personal loyalties.

Analysis of a great number of publications on the topic showed that there are few studies of motivational sphere at neurotic disorders.

This article provides an analysis of achievement motivation patterns of individuals that belong to the number of patients of "little psychiatry", i.e. patients who have had a neurotic and psychosomatic disorder. Interest to investigation of precisely these medical and psychological problems associated with greater realism, in our view, of task of changing patterns of pathological motivation in these patients.

\section{Literature review}

Motivational (need) approach to the emergence of neuroses can be found in the works of Freud, Alfred Adler, Erich Fromm Karen Horney, and other representatives of psychoanalysis, as well as in the works of thinkers of humanistic of existential tradition, in particular, Maslow, 
Frankl $[4,5]$.

Psychasthenic disorders the main difficulty in motivating is passage through "internal filter" of emerging ideas and motives, bearing intrusive nature. With high requirements for its moral standing and awareness of the absurdity of obsessions and impulses, the patient experiences unpleasant feelings such as doubt, anxiety and uncertainty. For example, an obsessive fear of infection, accompanied by an endless hand washing is characterized by the fact that the patient understands that his actions are absurd and the fear is irrational but he continues to behave as before, to reduce mental stress. That it is the basis of obsessive-compulsive disorder [6]. Psychasthenic has difficulty in making a decision and is characterized by fluctuations in the choice of target actions, ways to achieve it. However to move from target selection to the intention and implementation is even more difficult for him. Psychosomatic equivalents of mental disorders are a common form of expression of the latter. Initially, the concept of "psychosomatic" united diseases, where adverse effects of stressful (coronary heart disease, hypertension, gastric ulcer and duodenal ulcers, bronchial asthma) have an important role. Today the term has two meanings, with the one is related to its use in medicine and the second is a disease in which the important role is played by psychological factors $[6,7]$.

The basis of psychosomatic disorders is primarily a bodily reaction to the conflicting feelings associated with morphological changes and established by pathological alterations in organs. Appropriate predisposition may influence the choice of the organ. This group includes the following classic pattern of psychosomatic disorders: asthma, ulcerative colitis, essential hypertension, atopic dermatitis, rheumatoid arthritis, duodenal ulcer. Such psychosomatic diseases like hypertension, as already mentioned, are characterized by the manifestation of specific features of motivational sphere, including achievement motivation. Such patients tend to have a combination of high "achievement motivation", low prospect of success and fear of failure is high. The main radical of neurotic and psychosomatic disorders is anxiety. Anxiety as a personal disposition is closely linked to the achievements and motives of avoiding failure [2].

The purpose of current research is to reveal correlation between achievement motivations with personal factors in mental disorders.

3. Material and methods. The research sample included patients of psychotherapeutic branch of the National scientific and practical centre of psychiatry, psychotherapy and addiction - 65 subjects. Among them patients with: diagnosis of neurasthenia - 21 subjects, obsessive-compulsive disorder -24 , hypochondriacally disorder - 20.

Our study was carried out using the following methods:

Test by Hekhauzen. Given test is a psychological tool for the study of the strength and direction of human motives and relates to advantageously two main aspects motivation for success and motivation of avoiding failure [5].

Inclusion of this test to the complex of methods of empirical study of persons' with mental disorders achievement motivation is due to the following, from one side, the relative "ease" of the study, on the other hand, wellestablished reputation of this method among professionals in the field of achievement motivation. The first factor was particularly significant in conduct a study with subjects related to the category of persons with mental disorders. Hekhauzen relied on the concept of Atkinson and McClelland, according to which the diversity of motivational sphere can be reduced to two main structural components, namely: motivation, aimed at achieving success and motivation aimed at avoiding failure. As an stimulus material, which trigger surveyed unconsciously to discover the strength and direction of his motivational sphere, Hekhauzen proposed to use 6 cards with pictures differing from the test TAT mainly in that they depict fragments of the service and industrial situations. According scenes that subject has created using a "key" those basic positions (symptoms) could be identified; a simple calculation allows us to calculate and compare the two leading motive - aimed at achieving the objectives and avoiding failure $[9,10]$.

Test "Diagnostics of motivational structure of personality" by Milman. For the study of achievement motivation, we needed to get information about the features of motivational sphere of personality and its structure. We were interested in the question of the quality content of motivational sphere and its components, reflecting the focus on certain areas of life. This objective corresponds to the use of techniques "Diagnostics of motivational sphere of personality" [8]. The technique allows diagnosing motivation (MP) and emotional (EP) profiles of personality.

Questionnaire "Big Five". The complex of research methods includes one of the most commonly used personality questionnaires - "Big Five". This method provided an opportunity to obtain information about the major factors of personal characteristics of the subjects in order to analyse the possible relationship of these factors with different characteristics of their achievement motivation. The developers of this psycho-diagnostic technique are P. Howard, P. Medina and J. Howard. It is intended for the rapid diagnosis of the five personality factors: negative emotionality, extraversion, openness, agreeableness, and conscientiousness. Professor Burlachuk and Korolev made adaptation of this technique on the base of the Kiev National University [3].

Characterological symptoms, which can be determined from subject with the help of the primary factors of the "Big Five", are listed in the graph results of the research. On the left of each primary factor are the personality traits that, according to the "Big Five" correspond to high values of scores, on the right personality trait with low scores.

4. Results and discussion. Research of correlation achievement motivation with personal factors in mental disorders was conducted in following subgroup: 1) Persons with a diagnosis of "neurasthenia"; 2) Persons with a diagnosis of "obsessive-compulsive disorder"; 3 ) Persons with a diagnosis of "undifferentiated somatoform disorder"; 4) Those with a diagnosis of "hypochondriacal disorder"; 5) Persons with a diagnosis of "dissociative conversion disorder"; 6) Persons with a diagnosis of "mixed anxiety and depressive disorder".

Table 1 presents the correlations of achievement moti- 
vation and personality factors in all six subgroups.

Table 1. - Correlations of indicators with achievement motivation of personal factors in a group of individuals diagnosed with F-40 F-48

\begin{tabular}{|l|l|l|l|l|l|l|}
\hline \multirow{2}{*}{ Personal factors } & \multicolumn{6}{c|}{ Correlation with the achievement motivation by subgroups: } \\
\cline { 2 - 8 } & 1 & 2 & 3 & 4 & 5 & 6 \\
\hline Extraversion-introversion & $-0.479^{*}$ & - & - & - & - & $0.386^{*}$ \\
\hline Search for impressions- impressions avoidance & $-0.440^{*}$ & - & - & - & - & - \\
\hline Manifestation of guilt-avoidance & - & - & - & - & - & $0.409^{*}$ \\
\hline Self-control - impulsivity & - & $-0.379^{*}$ & - & $-0.402^{*}$ & $0.361^{*}$ & - \\
\hline Perseverance-lack of perseverance & - & - & - & - & $0.353^{*}$ & - \\
\hline Responsibility- irresponsibility & - & $-0.354^{*}$ & - & $-0.369^{*}$ & - & - \\
\hline Precaution- carelessness & - & - & - & $-0.363^{*}$ & - & - \\
\hline Self-control - lack of self-control & - & $-0.359^{*}$ & - & $-0.353^{*}$ & - & - \\
\hline Emotional instability & - & - & $-0.363^{*}$ & - & - & $-0.364^{*}$ \\
\hline Anxiety - carelessness & - & $-0.489 * *$ & - & - & - & $-0.358^{*}$ \\
\hline Tension-relaxation & $-0.379^{*}$ & $-0.352^{*}$ & $-0.354^{*}$ & - & - & - \\
\hline Depressive-emotional comfort & - & - & $-0.381^{*}$ & - & - & $-0.373^{*}$ \\
\hline Self-criticism- self-sufficiency & - & $-0.415^{*}$ & - & - & $-0.364^{*}$ & - \\
\hline Lability - emotional stability & - & - & $-0.367^{*}$ & - & $-0.403^{*}$ & - \\
\hline Expressiveness-practicality & - & - & - & - & - & - \\
\hline Sensitivity-insensitivity & $-0.352^{*}$ & - & - & - & $-0.392^{*}$ & - \\
\hline Plasticity-rigidity & - & - & - & - & - & $0.377^{*}$ \\
\hline
\end{tabular}

As you can see, for various subgroups group of patients with a diagnosis of F-40 - F-48 there is a different data. This result is consistent with the data available in relation to the personal characteristics of persons belonging to different groups and nosology and has those or other neurotic disorders. Thus, the average profiles, compiled on the basis of Minnesota multi-personality questionnaire are different, for example, in patients with hysteria, psychasthenia, hypochondria, etc. [11].

Obviously, the achievement motivation of these categories of persons associated with different personality factors.

Let us briefly consider the results for each subgroup.

1) Achievement motivation and its relationship with personality factors in patients with a diagnosis of "neurasthenia". Specific character of achievement motivation in this category of people, as we can see, is due to its level with such features as "extroversion-introversion" ($0.479 *)$, in particular - "search for impressions - impressions avoidance" $(-0.440 *)$, "tension -relaxation" (-0.379 *) and "sensitivity - insensitivity" $(-0.352 *)$. These results are explained, apparently, by the compensatory mechanisms, which function in patients with neurasthenia. Tension (opposite pole of relaxation) as well as an increased sensitivity of pathogens is key personal characteristics that impede the full achievement motivation formation.

2) Achievement motivation and its relationship with personality factors in patients with a diagnosis of "obsessive-compulsive disorder".

This group, as well as in the group with the diagnosis of "mixed anxiety and depressive disorder", revealed the largest number of interdependencies achievement motivation and personal factors. These are the factors: "selfcontrol-impulsivity" $(-0.379 *)$ and the scale factor of the "responsibility-irresponsibility" (-0.354*); "lack of selfcontrol-self-control" $(-0.359 *)$; such scale factor as "emotional instability-emotional stability" as "anxietycarelessness (-0.489**), "stress-relaxation" (-0.352*) and "self-criticism-self-sufficiency" (-0.415*).
3) Achievement motivation and its relationship with personality factors in patients with a diagnosis of "undifferentiated somatoform disorder".

This group identified indicators of such bonds achievement motivation as a factor "emotional instabilityemotional stability" $(-0.363 *)$, with the scales of this factor "stress-relaxation" (-0.354*), “depressionemotional comfort" $(-0.381 *)$ "emotional liabilityemotional stability" $(-0.367 *)$. In other words, the achievement motivation in undifferentiated somatoform disorder is formed at a relatively high level, with relatively more severe emotional stability as a whole and its parameters such as relaxation, emotional comfort, emotional stability.

4) Achievement motivation and its relationship with personality factors in patients with a diagnosis of "hypochondriac disorder".

In the group of patients with hypochondriac disorder the factor of achievement motivation "self-control" ($0.402 *)$ and the scale factor of the "responsibility-lack of responsibility" (-0.369*), "forethought-complacency" ($0.363 *)$, "self-control-lack of self-control" $(-0.353 *)$ is on the fore front.

5) Achievement motivation and its relationship with personality factors in patients with a diagnosis of "dissociative conversion disorder".

This group revealed a positive correlation with performance indicators of achievement motivation factor "lack of self-control-self-control" $(0.361 *)$ and the scale of this factor "perseverance-lack of perseverance" $(0.353 *)$ and negative correlations of scale factor "emotional instability-emotional sustainability", "self-criticism-selfsufficiency"(-0.364*) and "emotional lability-emotional stability" $(-0.403 *)$ and the scale factor "expressivenesspracticality" and "sensitivity-insensitivity" (-0.392*).

6) Achievement motivation and its relationship with personality factors in patients with a diagnosis of "mixed anxiety and depressive disorder".

This group of persons is characterised by negative correlations with achievement motivation factor "extraversion-introversion" $(-0.386 *)$ and the scale of this factor 
"the feeling of guilt-guilt avoidance" $(-0.409 *)$, with the factor of "emotional instability-emotional stability" ($0.364 *)$ and the scale factor of the "anxiety-carelessness" $(-0.358 *)$ and "depression - emotional comfort" (-0.373 $*)$, as well as positive correlation with a scale factor of "expressiveness-practicality" and "plasticity - rigidity" $(0.377 *)$.

5. Conclusion. Thereby various links of achievement motivation with personal factors were found under various embodiments of neurotic disorders.

- In patients with a diagnosis of "neurasthenia" increase in indicators of achievement motivation occurs simultaneously with an increase in the level of introversion factor and decrease the level of sensitivity factors and tension. Specificity of achievement motivation in this category of people is due to its level with such features as "extroversion-introversion" $(-0.479 *)$, in particular "search for impressions - impressions avoidance" (-0.440 $*)$, "tension - relaxation" $(-0.379 *)$ and "sensitiveness insensitivity" $(-0.352 *)$.

- In patients with a diagnosis of "obsessivecompulsive disorder" achievement motivation is associated with factors such "self control - impulsivity" $(-0.379 *)$ and the scale factor of the "responsibility-irresponsibility" $(-0.354 *)$; "self-control - lack of self-control" (-0.359*); such scales factor "emotional instability - emotional stability" as "anxiety - carefree" (-0.489**), "tensionrelaxation" $(-0.352 *)$ and "self-criticism, selfsufficiency" $(-0.415 *)$.
- In patients with a diagnosis of "undifferentiated somatoform disorder" were found such ties indicators of achievement motivation with factor "emotional instability - emotional stability" $(-0.363 *)$, with the scales of this factor "tension-relaxation" $(-0.354 *)$, "depression and emotional comfort" $(-0.381 *)$, "emotional lability - emotional stability" $(-0.367 *)$.

- In the group of patients with a diagnosis of "hypochondriacally disorder" connection of achievement motivation with factor "self-impulsivity" $(-0.402 *)$ came to the forefront and the scale of this factor "responsibility lack of responsibility" $(-0.369 *)$, "forethought - complacency" $(-0.363 *)$, "self control - lack of self-control" ($0.353 *)$.

With the development of the pathological process in patients develop specific personality and behavioural patterns associated negatively with achievement motivation. Compensatory development opposite personality traits can be seen as an option to adapt to the disease and the complex bio-psycho-social effort to restore its own functionality. The positive pole of achievement motivation is associated with characteristics opposite to those, which reflect the development of pathological patterns. Mechanisms of adaptation to the existing psychiatric problems related to the compensation of the "weak" personality characteristics. Increased motivation to achieve in the mental pathology is possible with a shift in the personal organization of the poles of the "weak" personality traits to the opposite poles.

\section{REFERENCES}

1. Bandura, A. Self-efficacy: The exercise of control / Times Books, 1997. 604 p.

2. Brown, R. G. Negative symptoms: the 'pathology' of motivation and goal-directed behavior // Trends in Neurosciences. 2000. P. 412-417.

3. Burlachuk, L.F., Korolev, D.K. Adaptation of scale for diagnosis of five factors of personality // Questions of psychology. 2000. P. 126-134.

4. Gordeyeva, T.O. Psychology of achievement motivation. 2002. PP. 47-102.

5. Hekhauzen, H. Psychology achievement motivation. - St. Petersburg: Speech. 2001. -256 p.

6. Hiroto, D.S. Locus of control and learned helplessness // Journal of Experimental Psychology. 1974. P. 187-193.

7. Horney, K. Neurotic Personality of Our Time. 2002. 224 p.

8. Milman, V.E. Method of studying the motivational sphere of the person. 1990. P. $25-30$.

9. Tapalova O. B. Zhiyenbayeva, N.B. Integral Model of Communicative Subject of Modern Education // World Applied Sciences Journal (WASJ). 2014. 30 (12). P. 1821-1825.

10. Tapalova O. B. Modern aspects of achievement motivation analysis // Science and Education a New Dimension: Pedagogy and Psychology, 2014, II (18), Is. 37. P. 97-101.

11. Tapalova O. B., Burlachuk, L., Zhiyenbayeva, N. Psychodiagnostics of achievement motivation in obsessive-compulsive disorder // American Journal of Scientific and Educational Research, 2014. 1(4). II. P. 338-343.

\section{Исследование мотивации достижения при невротических и связанных со стрессом расстройствах}

\section{Н. Б. Жиенбаева, Б. Б. Бейсекеева, А. Е. Абдрахманов, О. Б. Тараlova}

Аннотация. В настоящей статье представлены результаты исследования мотивации достижения при невротических и связанных со стрессом расстройствах. Интерес к исследованию этой медико-психологической проблемы связано с показателями изменений мотивации достижения среди данной группы людей. В исследование были включены 65 респондентов. Исследование проводилось с использованием следующих методик: тест Хекхаузена, тест «Диагностика мотивационной структуры личности» Мильмана, тест «Большая пятерка» Полученные результаты исследования показывают, что невротические и связанные со стрессом расстройства у людей являются следствием внутреннего конфликта и беспокойства.

Ключевые слова: мотивация достижения, неврастения, ипохондрическое и обсессивно-компульсивное расстройство, тревога, депрессия. 